\title{
The Influence of FDI and Human Capital Inflow on Technological Progress
}

\author{
Hongbo Jiang ${ }^{1}$ \\ ${ }^{1}$ International College, Dongseo University, Busan 47011, Korea \\ Correspondence: Hongbo Jiang, International College, Dongseo University, Busan 47011, Korea.
}

Received: May 20, 2021

Accepted: June 28, 2021

Online Published: July 7, 2021

doi:10.5430/jms.v12n2p24

URL: https://doi.org/10.5430/jms.v12n2p24

\begin{abstract}
FDI and human capital flow, as an important path of international technology diffusion, is an important driving force for technological progress in a region. Using panel data of 30 provinces and cities in China, this paper examines the relationship between FDI, human capital flow and technological progress in different regions of China. The empirical results show that the two approaches play an important role in technological progress in different regions of China, but the contribution degree is different. Various regions should implement appropriate policies to make full use of the technology spillover effect of export and human capital flow to accelerate technological progress, and form a smooth domestic technology diffusion mechanism to accelerate the transmission of foreign RESEARCH and development, and finally promote the coordinated development of regional economy.
\end{abstract}

Keywords: FDI, human capital flow, technical progress, panel data

\section{Introduction}

The strengthening of the trend of global economic integration has promoted the international dissemination of knowledge and technology, so that developing countries do not have to rely solely on their weak technological innovation, but can achieve technological progress through international technology diffusion. FDI and human capital flows, as important routes of international technology diffusion, promote international technology transfer and diffusion among economies. Human capital flow is also an important channel for technological progress.

FDI technology spillovers are mostly studied on the overall impact of FDI on the technological progress of the host country, and rarely consider the subsequent impact of FDI in the host country (even if there is, it is limited to theoretical aspects). The personnel flow of the host country's employment in FDI enterprises plays an important role in the technological progress of the host country. When the local employees of FDI subsidiaries move to other local enterprises or jump ship to start their own new companies, the following three ways are mainly used to promote the technological progress of enterprises: technology spillover effect of employee mobility, cost saving effect and inter-enterprise competition incentive effect. Compared with the technology spillover of FDI, about the international flow of human capital in a country's technological progress research is relatively small, the human capital inflows to improve the human capital level of the recipients, manpower capital inflows through both direct and indirect impact on a country's technological progress, including direct way is refers to the human capital directly into a country from other countries; Indirect means that human capital flows out of a country and back into the country.

Since the reform and opening up, transnational direct investment and human capital flow have developed rapidly in China. According to statistics from the Ministry of Commerce, China attracted FOREIGN direct investment of us $\$ 92.395$ billion in 2008 , an increase of $23.58 \%$ over the previous year. China has been the developing country attracting the most FDI for 16 consecutive years. In 2008, the number of students studying in China exceeded 200,000 for the first time, with a total of 223,499 students from 189 countries and regions studying in China, an increase of $14.32 \%$ compared with 2007. The academic researches on human capital flow and technological progress mainly focus on the existence of human capital flow's impact on technological progress, and empirical studies are few. In this paper, panel data of 29 provinces and cities in China from 1985 to 2007 are selected to test the relationship between the two paths and China's technological progress, and try to answer the above questions. In this paper, the method of constructing foreign RESEARCH and development stock of LP (1996) is used to quantify the RESEARCH and development stock contained in FDI, and then the regression analysis between it and total factor productivity is carried out. 


\section{Literature Review}

As Krugman argues in Trade and Geography, "the flow of knowledge... leaves no literal evidence to measure or track." It is difficult to accurately examine technology spillovers. Therefore, empirical studies on technology spillovers of foreign investment often do not try to answer the question of how the spillovers occur or how to achieve, but only use indirect methods to explore whether the spillovers exist. Although Caves' study is the earliest empirical literature in this regard, it has not been focused on FDI until the 1990sThe study of technology spillover has really aroused wide academic interest. On the one hand, it is due to the rapid expansion of foreign direct investment in the world recently, and the urgent need for policy makers of various countries to analyze the economic impact of foreign investment; on the other hand, it is due to the improvement and wide application of new analytical tools such as panel measurement method. The conclusions drawn from a wide range of recent international studies, based on country-specific studies, show significant uncertainty. Some literatures confirm the existence of spillover effect of foreign technology, such as Kokko's study on Mexico, Hubert and Pain's study on Britain, etc. At the same time, there are many literatures, such as Aitken and Harrison's study on Venezuela, that do not find this kind of spill-over effect.

With the expansion of the scale of China's investment, domestic scholars' research on the technology spillover of foreign investment is also increasing. In terms of industry data research, Yao Yang used the data of the third National Industrial Census to study the impact of non-state-owned economic components on the technical efficiency of China's industrial sector. The results showed that compared with state-owned enterprises. The technical efficiency of foreign investment is generally more than $30 \%$ higher, and if the proportion of foreign enterprises increases by one percentage point, the technical efficiency of each enterprise will increase by 1.14 percentage points. He Jie et al. studied the spillover effect of foreign capital on industrial sector by using the time series data of industrial sector from 1985 to 1996 and Feder decomposition method of two sectors. The results showed that the positive spillover effect of foreign capital enterprises on domestic enterprises was "real", but the spillover effect had great fluctuations. In terms of research based on regional data, Shen Kunrong's cross-sectional analysis of the correlation between the total foreign capital and total factor productivity in 1996 shows that every unit increase in the proportion of foreign capital to GDP can bring 0.37 units of total factor productivity growth. Based on the theoretical framework of endogenous growth, Shen Kunrong et al. further tested the panel data of 29 provinces and cities by SUR method, and also came to the conclusion that foreign investment promotes economic growth through technology spilt over. He Jie using the national 28 provinces and regions in five consecutive years of relevant data, for further quantitative analysis, the technological spillover effect of the results showed that foreign investment in the provinces have positive technological spillover effect, but in each region in accordance with the economic development level is divided into more than a certain economic level (threshold), and in the two groups did not reach the threshold level, the spillover effect of each group showed a larger difference. Pan Wenqing in 1995-2000 foreign spillover effect to industry analysis, found that foreign investment in general for the domestic sector spillover effect is positive, but further study with, east and west parts of the world shows that spillover effect on the regional distribution differences, including the positive spillover effect of eastern and western regions is less, while the central region is more significant.

The above literatures, whether international or domestic, all reflect a common point, that is, the technology spillover effect is often very different in different regions. Although this is related to the selection of methods and data, the differences in regional conditions seem to be the more critical explanation. Therefore, since the late 1990s, some scholars have gradually begun to introduce the concept of absorptive capacity into the study of technology spillovers. Borensztein et al. used transnational data to analyze how FDI affects economic growth. In this paper, the author introduced the absorptive capacity index into the analysis equation for the first time, and concluded that the spillover effect of FDI would occur only when human capital reached a minimum level. With the help of the concept of absorptive capacity, the uncertainty of previous research conclusions can be explained to some extent: there are differences in absorptive capacity among different regions. In domestic literature, Lai Mingyong et al. also began to apply the concept of absorptive capacity to study the problem that there are great differences in the spilt effect of foreign investment technology in different regions. In this paper, with the help of endogenous growth model, Lai Mingyong et al. try to prove the key influence of absorptive capacity on the technology spillover effect of foreign investment theoretically.

Undoubtedly, the study of FDI technology spillover from the perspective of absorptive capacity has become an important research direction in this field in recent years, which is very important for the in-depth understanding of the realization process of FDI technology spillover. In contrast, the relevant studies based on absorptive capacity in domestic literature are still very insufficient. Therefore, this paper will conduct an in-depth analysis of FDI 
technology spillover effect from an empirical perspective based on the concept of absorptive capacity along this direction.

\section{Specification of Empirical Model}

Firstly, based on the endogenous growth model, this paper establishes a theoretical basis that can be inferred for the testing model of technology spilt effect. Technological progress appears in the form of "capital broadening" in the model, that is, the creation of new capital goods represents technological innovation, while the total number of capital varieties represents technological level. Assuming that only one final consumer product is produced in the economy, the form of the production function is as follows:

$$
Y t=H \alpha t K 1-\alpha
$$

$\mathrm{H}_{\mathrm{t}}$ represents the human capital invested by the final sector, and $\mathrm{K}_{\mathrm{t}}$ represents the physical capital, which consists of a series of different types of capital goods. The capital stock in the economy at any moment is given by the following formula:

$$
K t=\left\{\int N O x(i) 1-\alpha d i\right\} 11-\alpha
$$

Here, $\mathrm{N}$ is the total number of capital goods available, and $\mathrm{x}$ (I) is the number of capital goods of type I. In an open economy with foreign capital, $\mathrm{N}$ will consist of two parts: $\mathrm{N}$ kinds of capital goods produced by domestic enterprises and $\mathrm{N} 3$ kinds of capital goods produced by foreign enterprises. Unitalize the prices of final consumer goods and assume that the final goods are either consumed or used on a one-to-one basis to produce intermediate capital goods.

Based on the above analysis model, we establish the following generalized empirical model:

$$
\text { tech }=F(F D I, H, \text { other factors })
$$

Among them, tech refers to the technical level of domestic industrial sector. As for which indicator to represent this variable, there are different methods in the existing literature. Some use the number of patents, others use the patent citation rate, but most of them use the total productivity T, F, P.Considering that many technologies of an enterprise are not or cannot be patented, but exist in secret or know-how form, in order to more fully reflect the state of the technology, this article will use T, F, and P to represent the level of technology.

Now let's look at the right-hand side of equation (1). FDI refers to the foreign capital flowing into the industrial sector. Considering the time-delay effect, we use the lag phase value in the empirical analysis. H stands for human capital, which is an important determinant of technological progress, not only because it is the basis of independent innovation, but also represents the ability to master the spillover of foreign investment in the case of the introduction of foreign capital, namely the absorptive capacity. Whether several forms of FDI technology spillover can be realized is closely related to the absorptive capacity of the host country. Having certain human capital is often a necessary prerequisite for mastering and applying advanced technology. In regions with low levels of human capital, foreign-funded enterprises may not be able to find partners with sufficient capacity to provide high-quality intermediates, so they must resort to the international market. As a result, domestic enterprises cannot obtain technology spillover from FDI through connection effect. Human capital also directly determines the ability to learn and imitate: in the face of advanced technology and equipment, the lack of knowledge and skills may make it impossible for domestic enterprises to master and improve, so as to apply the technology spilt from foreign capital.

In order to control the influence of other factors on the technological progress of domestic industrial sector, we also add two control variables, trade openness and investment ratio, into the test model. Trade and foreign capital are two equally important channels of international technology spillover. First, the greater the trade volume, the more opportunities for international exchange, the more information exchange, the more new technologies the country can learn from; Second, imports contain heterogeneous intermediate products that cannot be produced at home. The larger the imports, the more new knowledge will be gained through reverse research. Third, when exporting their own products, foreign buyers offer advice on how to improve the production process. In order to control the influence of international trade on the technological progress of domestic capital sector, the control variable of trade openness should be added. In addition to the indirect ways of technological progress such as foreign investment and trade, enterprises will also promote technological progress through the direct way of replacing equipment. In order to reflect the productivity improvement caused by the equipment input, we also add the investment rate as the control variable. In addition, due to different levels of economic development in different regions, there are differences in some basic conditions, such as financial market efficiency and market system perfection, etc. In order to reflect the impact of these factors on technological progress, corresponding control variables should be added.

However, it is actually difficult to find appropriate statistical variables to reflect factors such as market efficiency and 
institutional perfection. As a compromise, instead of looking for proxies for each of these factors, GDP per head is added. We believe that market efficiency and institutional perfection are closely related to regional economic development, and it is feasible to use per capita GDP, which represents the level of development, as a proxy indicator for these factors in econometric analysis.

\section{Source of the Data}

Let's look at explanatory variables first. The value of FDI is the actual annual inflow of foreign capital in each region. Since the regression equation uses the lagged value of one period, the value period of this variable is 1998-2002.In addition to the time delay effect, the use of the lag value is also to avoid the problem of endogeneity, that is, to avoid the situation of attracting foreign capital into the industry with higher technology level. If the lagging value is selected, the foreign capital becomes an exogenous variable. Logically speaking, there is no possibility for the current technology level to attract the foreign capital in the early stage. In this paper, to study the impact of foreign capital on technological progress of industrial sectors, the actual value of foreign capital utilized by industrial sectors should be selected. However, there are no statistics on the value of foreign capital utilized by industrial sectors at the regional level. Considering that foreign capital mainly flows to China's industrial sectors, the total annual actual value of foreign capital utilized by various regions is directly used here. In order to eliminate the impact of price changes, we first converted this value into RMB based on the annual central parity of exchange rate, and then adjusted it to the constant value of the price level in 1998 using the fixed asset price index, and took the natural logarithm of it.

The annual human capital stock of each region is expressed by the average years of education of the population of each region, and the specific calculation method is as follows: According to the education status of the population over 6 years old published in The China Statistical Yearbook every year, multiply the number of people with various educational experiences by the corresponding number of years of education to get the total number of years of education. Then divide this value by the total number of population (over 6 years old) to get the average number of years of education. Specifically, primary school is calculated by 6 years, junior high school is calculated by 9 years, high school is calculated by 12 years and university is calculated by 16 years. Since the National Bureau of Statistics did not release information on population education by region in 2002, the annual data were obtained using the average of the two years before and after.

The investment rate of each region should have chosen the proportion of the investment in fixed assets of the industrial sector to the added value of the industrial sector, but the previous figure was only published by the National Bureau of Statistics in 2004. As an alternative, the proportion of the total fixed asset investment of the whole society in GDP of the same year is selected here, which is highly correlated with it. From a methodological point of view, this does not adversely affect the analysis. The trade openness of each region is expressed by the proportion of import and export volume to GDP. Per capita GDP is directly given by the statistical yearbook and adjusted to the price level in 1998 according to the GDP index, and then the natural logarithm is taken.

\section{Empirical Analysis}

Since the panel data includes cross-section and time series data, the validity of parameter estimation is determined by the correctness of model setting. Therefore, the setting of the model needs to be tested first to get effective parameter estimation. The main test is whether the model parameters are the same constant in all cross section sample points and time.

$\mathrm{F}$ test is used to determine whether mixed estimation model or variable intercept model is adopted for the equation. If the variable intercept model is adopted, we will further determine whether fixed effects model or random effects model should be established through Hausman test. After the test, the value is less than the critical value only in the case of assuming the same slope but different intercepts. Therefore, the variable intercept model is adopted. Through the Hausman test, the fixed effect model is selected for regression analysis.

Generally speaking, we can use the relevant time series data of the industrial sectors of each province for regression analysis, and then further calculate the total factor productivity of each region. However, the time span of sample data in this paper is very short, so the results obtained by regression are of little significance. Considering the large cross-section dimension of the data (30 individuals), the panel method is appropriate in this case. There are three commonly used panel data analysis methods: pooling regression, fixed effect model and Random effect model.

Firstly, Wald F test was used to compare the aggregation regression with the fixed effects model, and the calculated F statistic was equal to 12.23 , which rejected the assumption that the intercept term in different regions was the same at the $1 \%$ level, so the fixed effects model should be used. On the other hand, breusch-Pagan L M test was used to 
compare the aggregate regression and random effects model, and the calculated test value was equal to 178.21, which exceeded the critical value of $1 \%$ significance level of chi-square distribution with 1 degree of freedom, so the random effects model should be used. The above results show that there are both fixed and random effects in the analysis model. So, how to choose? There's actually no hard and fast standard here. The judgment of the nature of sampled samples is a basis for model selection, but in practice, a large number of literatures are more dependent on Hausman test for judgment. According to the calculation, the Hausman test value is equal to 11.65, which rejects the null hypothesis of the random effects model at the significance level of $1.25 \%$, so the fixed effects model should be adopted finally.

\section{Conclusions}

This paper empirically tests the relationship between foreign investment and technological progress in China's industrial sector, and the results show that absorptive capacity is an important factor affecting the realization of technological spillover effect of foreign investment. Only when the absorptive capacity reaches a certain threshold level will the technology spillover effect of foreign investment be realized significantly. According to our rough calculations, technological progress in a region's industrial sector can benefit from foreign investment only when the average number of years of schooling (representing absorptive capacity) exceeds about 6.5 years. After 2000, all regions of China have basically exceeded this threshold value, but due to the different absorption capacity of different regions, there are great differences in the benefits from foreign capital entry. With regard to the above empirical analysis, there are two problems that need to be explained. First, about the specific connotation of absorptive capacity, this paper adopts the widely recognized human capital index. Although some scholars have expanded the concept to include factors such as financial market efficiency, intellectual property protection and so on, overgeneralization can erode the essence of the definition. Absorptive capacity refers to the ability to master and apply advanced technology, while financial market efficiency and intellectual property protection reflect the basic conditions conducive to the absorption of advanced technology, which should be a different concept. 2 it is due to the data obtained is far from accurate word to describe, for example, the calculation of human capital is difficult to take into consideration of the personnel flow influence, which may make the final analysis result produces certain deviation, as a result, we also hope to be able to look at from the perspective of qualitative quantitative analysis results, which focus on data reflects the fact that rather than the number itself.

From the above results, we can read some policy implications, first of all, to attract foreign investment will remain an important measure of economic development in the future. Although the entry of foreign capital has also produced some negative effects, but from the perspective of technological progress, the contribution of foreign capital is still worthy of recognition, especially in the electronic device manufacturing, information products manufacturing and other high-tech industries, foreign capital has become the main force of industry development. Continue to vigorously attract foreign investment, which is of positive significance for the technological progress of the domestic industrial sector. Secondly, to realize the diffusion and spillover of technology resources from multinational companies to domestic enterprises, the absorption capacity is the key factor, so the cultivation of human capital must be paid attention to. At present, China's human capital has some structural problems.

In recent years, the increase of human capital stock is mainly due to the expansion of higher education, but the problem of over-advanced education has gradually emerged. Although the increase of highly educated talents has improved the overall level of human capital, many talents are not consistent with the demand of economic growth. On the contrary, the apparent shortage of well-educated and trained workers capable of coping with advanced technology is a structural contradiction that needs to be taken seriously in education policy.

\section{References}

Aitken, B. J., \& Ann, E. H. (1999). Do Domestic Firms Benefit from Direct Foreign Investment. American Economic Review, 89(3), 605-618. https://doi.org/10.1257/aer.89.3.605

Borensztein, E., De Gregorio, J., \& Lee, J-W. (1998). How Does Foreign Direct Investment Affect Economic Growth?. Journal of International Economics, 45(1), 15-135. https://doi.org/10.1016/S0022-1996(97)00033-0

Caves, R. E. (1974). Multinational Firms, Competition and Productivity in Host - Country Markets. Economica, 1974, (41), 176-193. https://doi.org/10.2307/2553765

He, J. (2000). Further quantification of the spillover effect of foreign direct investment on China's industrial sector. The Journal of World Economy, (8), 29-36.

He, J., \& Xu, L. D. (1999). An empirical study on the spillover effect of foreign direct investment in China's industrial sector. World Economic Papers, (2), 16-21. 
Hubert, F., \& Pain, N. (2001). Inward Investment and Technical Progress in the United Kingdom Manufacturing Sector. Scottish Journal of Political Economy, 48(2), 134-147. https://doi.org/10.1111/1467-9485.00190

Kokko, A. (1994). Technology ,Market Characteristics , and Spillovers. Journal of Development Economics, 43(2), 279-293. https://doi.org/10.1016/0304-3878(94)90008-6

Krugman, P. (1987). Geography and Trade, Translated by Zhang, Z. J. Beijing: Peking University Press.

Lai, M. Y. (2005). Sources of economic growth: Human capital, RESEARCH and development and technology spillover. Social Sciences in China, (2), 32-46.

Pan, W. Q. (2003). Spillover effects of foreign investment on China's industrial sector: an analysis based on panel data. The Journal of World Economy, (6), 3-7.

Romer, P. (1990). Endogenous Technological Change. Journal of Political Economy, 98, 71-102. https://doi.org/10.1086/261725

Shen, K. R. (1999). Foreign direct investment and China's economic growth. Management World, (5), 22-34.

Shen, K. R., \& Geng, Q. (2001). Foreign direct investment, technology spillover and endogenous economic growth. Social Sciences in China, (5), 82-93.

Yao, Y. (1998). The influence of non-state-owned economic components on the technical efficiency of Industrial enterprises in China. Economic Review, (12), 29-35.

\section{Copyrights}

Copyright for this article is retained by the author(s), with first publication rights granted to the journal.

This is an open-access article distributed under the terms and conditions of the Creative Commons Attribution license (http://creativecommons.org/licenses/by/4.0/). 